\title{
Desoxy-D2PM: a novel psychoactive substance in convenience stores
}

Hong Kong Med J 2016;22:515

DOI: 10.12809/hkmj166018

To the Editor-Novel psychoactive substances (NPSs) are recently available unlicensed drugs that are chemically or pharmacologically similar to conventional drugs of abuse. Their rapid and protean emergence has created many challenges for clinicians, laboratories, social workers, and regulatory authorities. Our laboratory has repeatedly identified NPSs. ${ }^{1,2}$ We report the discovery of 2-(diphenylmethyl)-pyrrolidine (desoxy-D2PM), an NPS present in an over-the-counter slimming product available in local convenience stores.

Undeclared desoxy-D2PM was detected in a slimming product branded "B-finn" purchased in Thailand by a patient. Subsequently, we obtained a slimming product of the same brand in a local drugstore and detected the presence of desoxyD2PM. The Department of Health was notified and a product recall was initiated. ${ }^{3}$ Shortly after, desoxyD2PM was detected in the urine specimen of another unrelated patient.

Desoxy-D2PM is structurally related to methamphetamine, which inhibits noradrenaline and dopamine re-uptake. Desoxy-D2PM has been reported to have appetite suppressing, euphoric, and stimulant effects. ${ }^{4}$ Overdose of desoxy-D2PM may lead to violent behaviour, hallucinations, and sympathomimetic toxicity. ${ }^{4}$

In Hong Kong, desoxy-D2PM is yet to be listed as a dangerous drug under the Dangerous Drugs Ordinance at the time of writing. Nonetheless its ready availability in drugstores and convenience stores before the recall, and its presence in the urine of an unrelated patient, raise concern about its unintentional use by the general public. This case and our previous local reports of NPS ${ }^{1,2,5}$ highlight the importance of a toxicology surveillance system in Hong Kong.

Nike KC Lau, MB, ChB, MA

YK Chong, MB, BS, FHKCPath

Magdalene HY Tang, PhD

CK Ching, FRCPA, FHKAM (Pathology)

Tony WL Mak *, FRCPath, FHKAM (Pathology)

Hospital Authority Toxicology Reference Laboratory, Princess Margaret

Hospital, Laichikok, Hong Kong

* Corresponding author: makwl@ha.org.hk

\section{References}

1. Tang MH, Ching CK, Tsui MS, Chu FK, Mak TW. Two cases of severe intoxication associated with analytically confirmed use of the novel psychoactive substances 25B-NBOMe and 25C-NBOMe. Clin Toxicol (Phila) 2014;52:561-5.

2. Tang M, Ching CK, Tse ML, et al. Surveillance of emerging drugs of abuse in Hong Kong: validation of an analytical tool. Hong Kong Med J 2015;21:114-23.

3. Recall of slimming product with undeclared Western drug ingredients (with photo). 25 Jul 2016. The Government of the HKSAR press release. Available from: http://www. info.gov.hk/gia/general/201607/25/P2016072500603.htm. Accessed Aug 2016.

4. Dargan P, Wood D. Novel psychoactive substances: classification, pharmacology and toxicology. UK: Academic Press; 2013.

5. Poon WT, Lai CF, Lui MC, Chan AY, Mak TW. Piperazines: a new class of drug of abuse has landed in Hong Kong. Hong Kong Med J 2010;16:76-7. 